\title{
Combining the management of hydrological process and plant structure for waterbird habitat provision in wetlands
}

\author{
Xintian Qiu ${ }^{1}$, Hongrui LIU ${ }^{1}$, Xinan Yin ${ }^{1}$, and Jinglan Qin ${ }^{1}$ \\ ${ }^{1}$ Beijing Normal University
}

July 7,2020

\begin{abstract}
The survival of waterbirds depends heavily on habitat, particularly aquatic plants. Previous studies usually focused on the use of hydrological management to achieve protection and restoration of aquatic plants. However, the hydrological processes in many lakes have been greatly changed and their ecological objectives usually cannot be achieved by hydrological management alone. This study proposes a new method to satisfy waterbird habitat requirements, by combining the management of hydrological processes and plant structure. In this study, the Hongze Lake National Wetland Nature Reserve was taken as the research area. Based on the water levels that different hydrophytes require for survival, and on waterbirds' needs for foraging and nesting area, we determined plantable area and plant structures under the current hydrological process. We then set three representative hydrological process scenarios and determined appropriate plantable area and plant structures under these hydrological processes. The results show that the current hydrological process of Hongze Lake is not conducive to the planting of the hydrophytes needed by waterbirds. A combination of hydrophyte planting and hydrological process management, however, can effectively expand the area of these aquatic plants. Within the constraints of flood control, the water level in March should be reduced, and the water level in July should be increased as much as possible. Therefore, a management method is provided for aquatic plant restoration and waterbird habitat protection in wetlands.
\end{abstract}

\section{Hosted file}

Main docunment-Combining the management of hydrological process and plant structure for waterbird habit available at https://authorea.com/users/339408/articles/465637-combining-the-management-ofhydrological-process-and-plant-structure-for-waterbird-habitat-provision-in-wetlands

\section{Hosted file}

Table 1.docx available at https://authorea.com/users/339408/articles/465637-combining-themanagement-of-hydrological-process-and-plant-structure-for-waterbird-habitat-provisionin-wetlands 

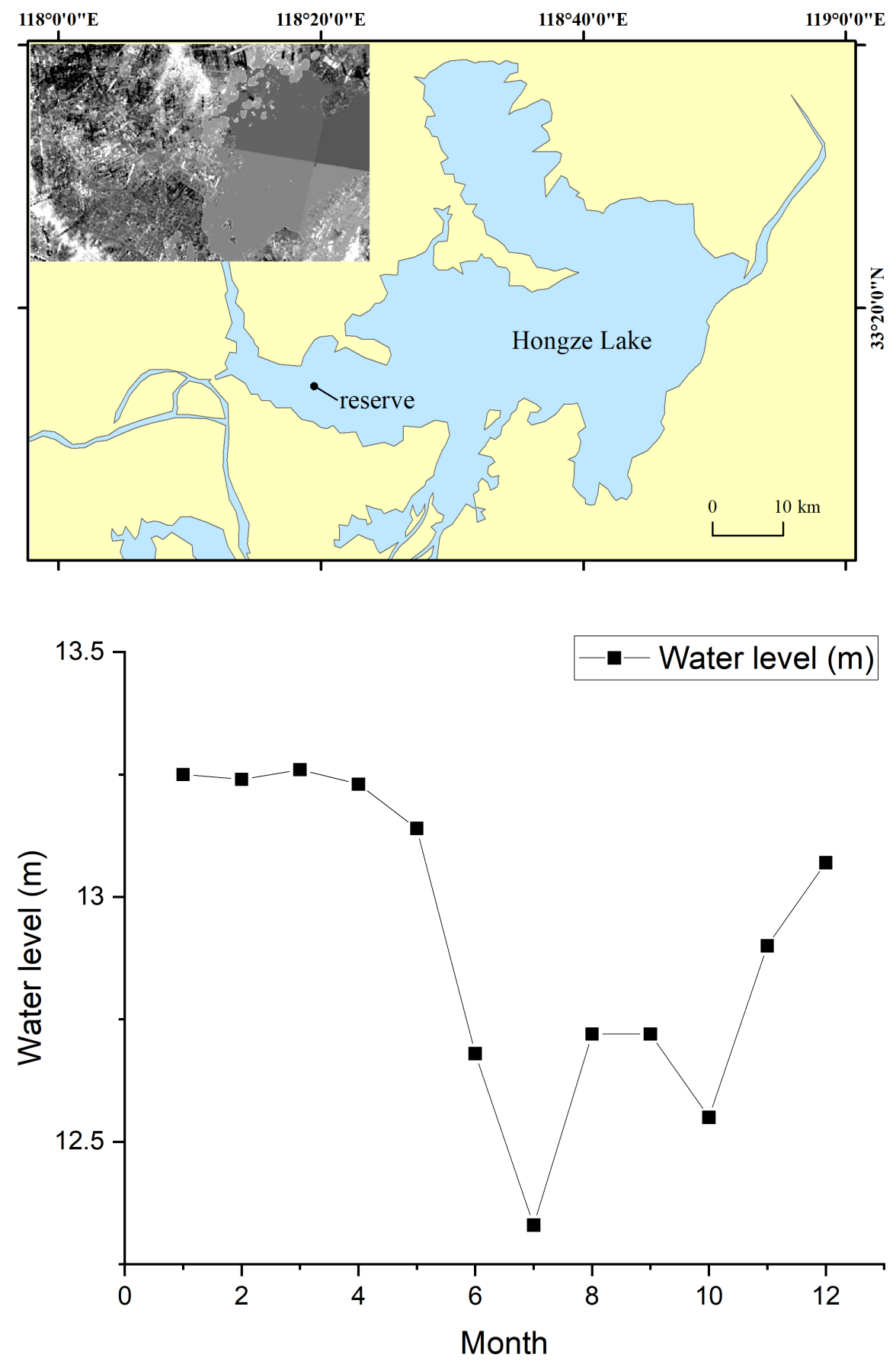

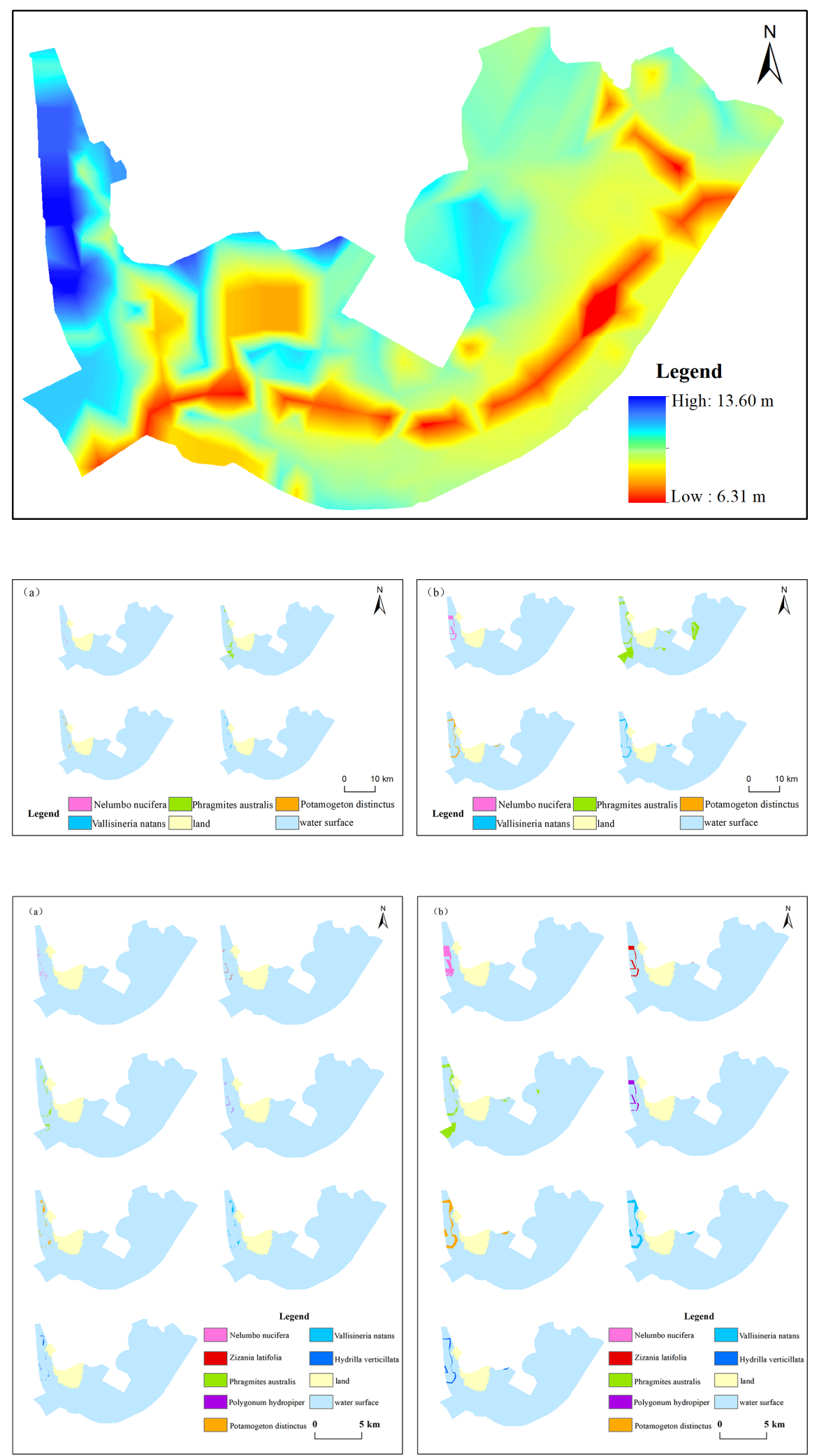

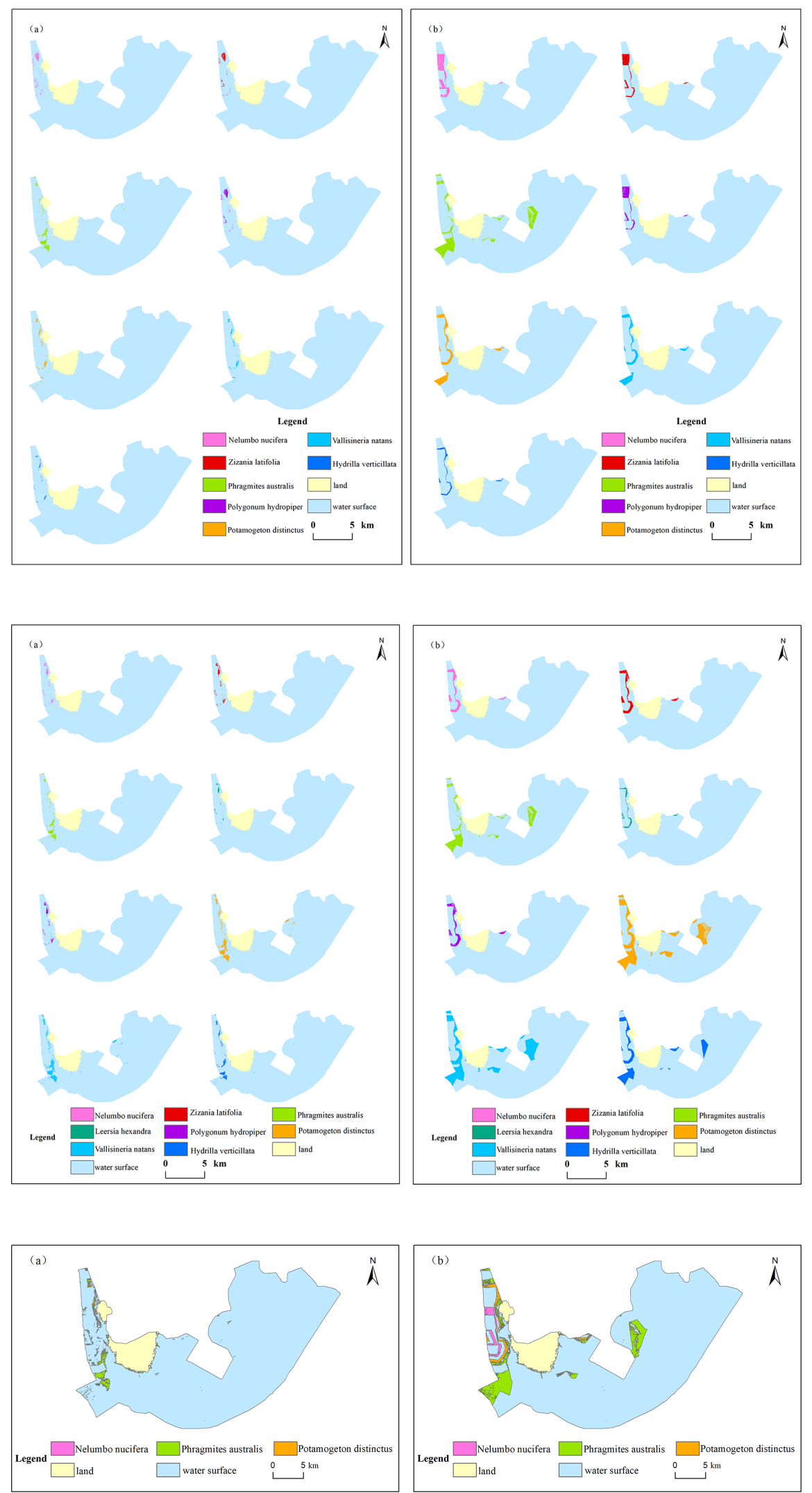

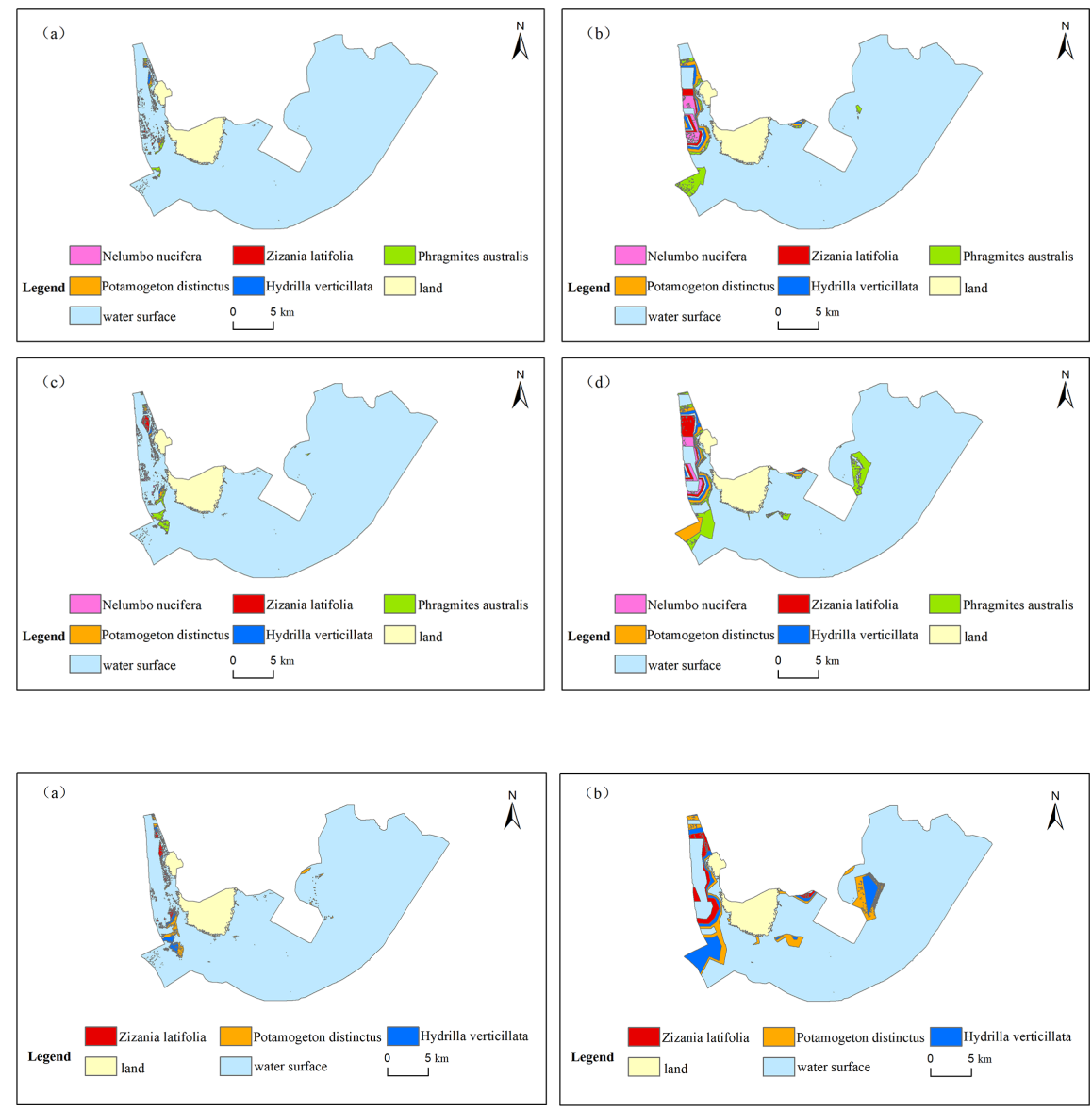